\title{
Cloning and characterization of hemolymph clottable proteins of kuruma prawn (Marsupenaeus japonicus) and white shrimp (Litopenaeus vannamei)
}

\author{
Winton Cheng ${ }^{\mathrm{a}}$, Inn-Ho Tsai ${ }^{\mathrm{b}, \mathrm{c}, * *}$, Chang-Jen Huang ${ }^{\mathrm{b}, \mathrm{c}}$, Pei-Chi Chiang ${ }^{\mathrm{a}}$, \\ Chia-Hsiung Cheng ${ }^{\mathrm{b}}$, Maw-Sheng Yeh ${ }^{\mathrm{d}, *}$
}

${ }^{a}$ Department of Aquaculture, National Pingtung University of Science and Technology, Pingtung, Taiwan

$\mathrm{b}$ Institute of Biological Chemistry, Academia Sinica, Taipei, Taiwan

'Institute of Biochemical Sciences, National Taiwan University, Taipei, Taiwan

${ }^{\mathrm{d}}$ Department of Food and Nutrition, Hungkuang University, Sha Lu, Tauchung, Taiwan

Received 19 January 2007; received in revised form 22 May 2007; accepted 31 May 2007

Available online 29 June 2007

\section{KEYWORDS}

Hemolymph

coagulation;

Clottable protein;

cDNA sequences;

Tissue expression

profile;

Shrimps

(Marsupenaeus

japonicus and

Litopenaeus

vannamei)

\begin{abstract}
The hemolymph clottable protein (CP) of Marsupenaeus japonica (designated as Mj-CP) was purified by a DEAE anion-exchanger and a Sepharose CL-6B gel filtration column. In the presence of $\mathrm{Ca}^{2+}$, it formed stable clots in vitro upon the addition of the hemocytes lysate containing transglutaminase. Results of gel filtration chromatography and SDS-PAGE indicated that Mj-CP mainly existed as disulfide-linked homodimers of $390 \mathrm{kDa}$. Specific primers were designed; PCR as well as RACE help to clone and sequence Mj-CP CDNA of $5660 \mathrm{bp}$. The predicted CP-precursor contains a signal peptide followed by a subunit of 1671 amino acids (isoelectric point 5.6), including two RGD motifs and three potential $\mathrm{N}$-glycosylation sites. Mj-CP is structurally $80 \%$ and $38 \%$ identical to the CPs of tiger shrimp and crayfish, respectively. Likewise, CP cDNA of white shrimp (Litopenaeus vannamei) was also cloned and sequenced; the predicted CP has 1666 amino acid residues and an isoelectric point of 5.2. Both CPs bear potential transglutaminase cross-linking sites, i.e. seven Ser-Lys-Thr repeats near the N-terminus, a Ser-and Gln-rich region in the middle, and polyGln $(n=8-11)$ near the C-terminus. Phylogenetic analyses of crustacean CPs and vitellogenins revealed divergent evolution of the two protein families. By RT-PCR, the subcuticular epidermis was identified as one of the major tissues that express CP in M. japonica. (c) 2007 Elsevier Ltd. All rights reserved.
\end{abstract}

Abbreviations: CP, clottable protein; Mj, Marsupenaeus japonicus; Lv, Litopenaeus vannamei; PCR, polymerase chain reaction; RACE, rapid amplification of cDNA ends; VTG, vitellogenin.

Note: The cDNA sequences of Mj-CP and Lv-CP were deposited in GenBank under accession Nos. DQ915453 and DQ984182, respectively.

**Also corresponding author.

*Corresponding author. Fax: +886426319176.

E-mail addresses: bc201@gate.sinica.edu.tw (I.-H. Tsai), yms1123@sunrise.hk.edu.tw (M.-S. Yeh). 


\section{Introduction}

Efficient immune systems and blood coagulation are of vital importance for the survival of both vertebrates and invertebrates. Hemolymph coagulation is part of the crustacean innate immune response; it prevents leakage of hemolymph from sites of injury and dissemination of invaders such as bacteria throughout the body [1]. Coagulation systems of invertebrates are distinct from those of vertebrates. Previous studies showed that diverse coagulation pathways have evolved in marine arthropods, e.g. the coagulation system in horseshoe crab [2] is different from that in crustaceans $[3,4]$. It has been shown that polymerization of clottable proteins (CPs) by the hemocyte transglutaminases triggers hemolymph clotting in insects [5] and crustaceans [6,7].

Several crustacean CPs have been purified from the hemolymph and characterized [8-14]. They are homodimeric glycoproteins of about $400 \mathrm{kDa}$ and bear no structural similarity to fibrinogen or the horseshoe crab coagulogen [2]. Stable clots of the CPs may form in the wound area by $\mathrm{Ca}^{2+}$-dependent transglutaminase from the hemocytes [15-18]. Crustacean CPs might also be involved in lipid transport $[6,13,19]$ in addition to the clotting role. Some features responsible for lipid binding have been identified in the low-resolution crystal structure of CP of lobster (Panulirus interruptus) [20].

Kuruma prawn (Marsupenaeus japonicus) and white shrimp (Litopenaeus vannamei) are economically important species cultured in Taiwan and southeastern Asia. Herein, we solved the complete nucleotide sequences of CP CDNAs of both shrimp species and characterized the purified $\mathrm{CP}$ of M. japonicus. Being the substrates for hemocyte transglutaminases, both CPs contain structural elements involved in the cross-linking reactions and these were examined and compared with those in other crustacean CP. CP expression levels in various $M$. japonicus tissues were also investigated by RT-PCR. Moreover, amino acid sequences for crustacean CPs and vitellogenins (VTGs) [21-26] were subjected to phylogenetic analysis, and their evolutionary relationships were discussed.

\section{Materials and methods}

\subsection{Hemolymph and hemocyte lysate}

Shrimps (20-25g body weight) were purchased from local markets and kept in aerated seawater. The hemolymph $(0.6-1 \mathrm{ml})$ was withdrawn using a $23 \mathrm{G} 2.5 \mathrm{ml}$ syringe containing $0.06-0.1 \mathrm{ml}$ anticoagulant as described previously [27]. Hemocytes were immediately spun down at $300 \mathrm{~g}, 4^{\circ} \mathrm{C}$ for $10 \mathrm{~min}$, and the supernatant was pooled for preparing the $\mathrm{CP}$. The pellet was washed once and then hypotonically lysed in $1 \mathrm{ml}$ of $10 \mathrm{mM}$ Tris- $\mathrm{HCl}(\mathrm{pH} \mathrm{7.5)}$. The hemocyte lysate was centrifuged at $12,000 \mathrm{~g}$ at $4{ }^{\circ} \mathrm{C}$ for $30 \mathrm{~min}$ and the supernatant was collected and used in the same day.

\subsection{Protein purification and clotting assay}

Shrimp plasma was first dialyzed against $50 \mathrm{mM}$ Tris- $\mathrm{HCl}$, $1 \mathrm{mM}$ EDTA, pH 8.0 (TE buffer) for $14 \mathrm{~h}$ at $4{ }^{\circ} \mathrm{C}$. It was subjected to ion exchange chromatography at $4{ }^{\circ} \mathrm{C}$ with a TSK DEAE-650 (s) column $(2.5 \times 9 \mathrm{~cm})$ equilibrated with TE buffer at linear $\mathrm{NaCl}$ concentration ranging from 0 to $0.35 \mathrm{M}$ $\mathrm{NaCl}$ [28]. The fractions from TSK DEAE-650 (s) column chromatography with clotting ability were further concentrated and subjected to gel filtration chromatography with a Sepharose CL-6B column. The elution buffer was $1 \mathrm{mM}$ EDTA in $50 \mathrm{mM}$ Tris- $\mathrm{HCl}(\mathrm{pH} \mathrm{8.0)} ; 2.2 \mathrm{ml}$ fractions were collected at a flow rate of $16 \mathrm{ml} / \mathrm{h}$ at $4{ }^{\circ} \mathrm{C}$. Protein concentrations were determined by the Bradford method [29] using bovine serum albumin as standard. For clotting assay, the purified sample was dialyzed; then a $0.1 \mathrm{ml}$ aliquot was transferred to a test tube and the hemocyte lysate was added [11]. After incubating for $1 \mathrm{~h}$ at room temperature, the test tube was tilted to check whether the sample was clotted.

The native molecular weight of CP of $M$. japonicus (Mj-CP) was also estimated by its elution volume on a Sepharose CL-6B gel filtration column, based on a calibration plot of "ratios of the elution volume to the void volume" versus $\log$ (molecular weight of the marker).

\subsection{SDS-PAGE and amino acid sequencing}

Purified Mj-CP was subjected to SDS-PAGE [30] with a $5 \%$ acrylamide gel, and stained with Coomassie brilliant blue R250. Enzymatic oligomerization of $\mathrm{Mj}$-CP was analyzed by $2.5 \%$ polyacrylamide/agarose gel. Markers used were myosin $(212 \mathrm{kDa}), \quad \beta$-galactosidase $(116 \mathrm{kDa})$, phosphorylase $\mathrm{B}$ $(97 \mathrm{kDa})$, bovine serum albumin $(66 \mathrm{kDa})$, catalase $(57 \mathrm{kDa})$, and aldolase $(40 \mathrm{kDa})$ from Promega Co., USA.

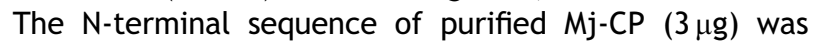
determined with a gas-phase sequencer coupled with an online HPLC system (Model 477A, Applied Biosystem, USA).

\section{4. cDNA synthesis and cloning}

Standard procedures in molecular biology were used for the preparation of plasmid DNA, restriction enzyme digestion, and DNA transformation to bacteria [30]. Total RNA was prepared from the gills of kuruma prawn and white shrimp separately, using the RNAzol B kit (Biotecx, Friendswood, TX, USA) [31]. mRNA was purified using a QuickPrepR Micro mRNA purification kit (Amersham Pharmacia, Freiburg, Germany). The first-strand cDNA was synthesized using oligo(dT)-primer and random primers, and it was used as templates in subsequent polymerase chain reaction (PCR) [32].

To specifically amplify Mj-CP cDNAs, we used degenerate primers designed based on its highly conserved amino acid sequences: e.g. QPPQVMK (i.e. N-terminal sequence or Mj1), MEEDIQR (Mj2), FMEEDIQ (Mj3), TFTNQTLE (Mj9), EIDATKC (Mj10) and YDCTEWVY (Mj15) (Table 1) and Lv1-Lv11 as shown in Table 2. The PCR products were purified and ligated into PGEM-T (Promega). Each clone was sequenced using AmpliTaq DNA polymerase and fluorescent dideoxynucleotides on a DNA sequencer (Applied Biosystems Model 310) [33].

\subsection{Rapid amplification of cDNA ends (RACE)}

The $5^{\prime}$ ends of Mj-CP and Lv-CP mRNAs were completed by a 5'-RACE system (Version 2.0, Invitrogene, Carlsbad, CA, 
Table 1 Primers used in the cloning of Mj-CP gene

\begin{tabular}{|c|c|c|c|}
\hline Primers & Sequence & $\operatorname{Tm}\left({ }^{\circ} \mathrm{C}\right)$ & Position \\
\hline Mj1 & 5' CARCCNGGNCTNGARTAYCARTAY $3^{\prime}$ & 56.8 & 127 \\
\hline Mj2 & $5^{\prime}$ TTYATGGARGARGAYATHCA $3^{\prime}$ & 48.7 & 637 \\
\hline Mj3 & 5' CGYTGDATRTCYTCYTCCAT 3' & 49.6 & 640 \\
\hline Mj4 & $5^{\prime}$ CGACAGGTGACCTGGAGACGTCTTGGCC $3^{\prime}$ & 62.8 & 751 \\
\hline Mj5 & 5' GTTCTCCTGACGGACCAGAGTGTGTCC $3^{\prime}$ & 64.3 & 794 \\
\hline Mj6 & 5' GTGTACTTGCTGCTGTGGATCTGCAGG 3' & 65.8 & 855 \\
\hline Mj7 & 5' GAGCTCCGTGGCATCCTACCTCATCC 3' & 64.3 & 900 \\
\hline Mj8 & 5' GGACACGCACCGAAGGATCGAACAGG 3' & 64.3 & 931 \\
\hline Mj9 & 5' TCNAGNGTYTGRTTNGTRAANGT 3' & 55.2 & 1016 \\
\hline Mj10 & 5' GARATHGAYGCNACNAARTG 3' & 51.1 & 4081 \\
\hline Mj11 & $5^{\prime}$ TCCTTGATGATGGACACGGCATAAGG 3' & 59.5 & 4138 \\
\hline Mj12 & $5^{\prime}$ GAGTGAAGAATGGATTCACCCACACC $3^{\prime}$ & 59.5 & 4176 \\
\hline Mj13 & 5' GCTACTACACGGACTCCAGCCTCTTCG $3^{\prime}$ & 64.3 & 4676 \\
\hline Mj14 & $5^{\prime}$ ACATCTGCACTCACTTCACTTACGAGC $3^{\prime}$ & 59.7 & 4784 \\
\hline Mj15 & $5^{\prime}$ TANACCCAYTCNGTRCARTCRTA $3^{\prime}$ & 55.4 & 4841 \\
\hline
\end{tabular}

$R=A / G, S=C / G, Y=C / T, H=A / T / C$.

Table 2 Primers used in cloning of Lv-CP gene

\begin{tabular}{llll}
\hline Primers & Sequence & Tm $\left({ }^{\circ} \mathrm{C}\right)$ & Position \\
\hline Lv1 & 5' TTYATGGARGARGAYATHCA 3' & 48.7 & 639 \\
Lv2 & 5' TGGAAGACTTGCTAGTCTTCGATGTGG 3' & 59.7 & 694 \\
Lv3 & 5' GAACGTTCGCCAGTTGACCTGGAGACG 3' & 766 \\
Lv4 & 5' GAAGGATCGAGCAAGCCGTGGTGGAGG 3' & 64.3 & 949 \\
Lv5 & 5' TCNAGNGTYTGRTTNGTRAANGT 3' & 65.8 & 1023 \\
Lv6 & 5' GARATHGAYGCNACNAARTG 3' & 55.2 & 4068 \\
Lv7 & 5' GTTCCTTGATGATGGACACGGCATAGG 3' & 51.1 & 4126 \\
Lv8 & 5' GTGCAGGACACTGGCGTGCGACCGACG 3' & 59.5 & 4226 \\
Lv9 & 5' CATCCAACGACATGGTAGGACCTAAGG 3' & 4633 \\
Lv10 & 5' GATGTTGACGCTACCAGGAGGACTGC 3' & 59.5 & 4752 \\
Lv11 & 5' TANACCCAYTCNGTRCARTCRTA 3' & 61.3 & 62.8 \\
\hline
\end{tabular}

$\mathrm{R}=\mathrm{A} / \mathrm{G}, \mathrm{S}=\mathrm{C} / \mathrm{G}, \mathrm{Y}=\mathrm{C} / \mathrm{T}, \mathrm{H}=\mathrm{A} / \mathrm{T} / \mathrm{C}$.

USA). Briefly, total RNA was isolated from both shrimps. The first-strand cDNA was synthesized by reverse transcriptase (SperScript II RT) using Mj4 primer or Lv4 and $5 \mu \mathrm{g}$ of total RNA. The RNA template was removed by RNase and purified with S.N.A.P. column (Invitrogene, Carlsbad, CA, USA). The synthesized cDNA was further homopolymeric tailed by terminal deoxynucleotidyl transferase and dCTP, and then amplified with abridged anchor primer (AAP, 5' GGCCACGCGTCGACTAGTACGGGII GGGIIGGGIIG 3') and Mj3 primer or Lv3 primer. An aliquot of the CDNA products was diluted 1:100 and subjected to nested PCR with abridged universal amplification primer (AUAP, 5' GGCCACGCGTCGACTAGTAC $3^{\prime}$ ) and Mj2 primer or LV2 primer. Each of the 35 cycles run on the thermocycler was $94{ }^{\circ} \mathrm{C}$ for $30 \mathrm{~s}, 55^{\circ} \mathrm{C}$ for $30 \mathrm{~s}$, and $72^{\circ} \mathrm{C}$ for $1.5 \mathrm{~min}$, except the first and last cycles. The first cycle included an extended $(2 \mathrm{~min})$ denaturation period during which polymerase was added, while the last cycle had an extended (10 min) elongation period. PCR products were then cloned into PGEM-T vector (Promega) and sequenced.

\subsection{Phylogenetic analysis and hydropathic profiling}

Sequences of crustacean CPs and VTGs were retrieved by program BlastP [34]. Their amino acid sequences were aligned by the program CLUSTAL W [35]. A phylogenetic tree was built by the program PHYLIP (http://www.evolution. genetics.washington.edu./phylip.html) [36]. The degree of confidence of the lineage at each node was determined by the bootstrap analyses of 1000 replicates [37]. The hydropathic profile of the Mj-CP sequence was plotted following the method of Kyte and Doolittle [38]. Windows of seven residues were used to calculate the average hydrophobicity for the central residue.

\subsection{RNA isolation from various tissues and RT-PCR}

Total RNA was isolated from the central nervous system (CNS), gill, heart, hemocyte, hepatopancreas, intestine, 
lymphoid organ, eyestalk, sub-cuticular epidermis, and muscle of M. japonicus using the RNAzol reagent (Biotecx, Friendswood, TX, USA). First-strand CDNA was amplified from $2 \mu$ g total RNA using 10 pmol oligo-dT primer in a $25 \mu \mathrm{L}$ reaction containing $30 \mathrm{U}$ RNasin (Promega), $1 \mathrm{mM}$ dNTP, $10 \mathrm{mM}$ dithiothreitol, and $300 \mathrm{U}$ Superscript II (Life Technologies). After incubating at $42^{\circ} \mathrm{C}$ for $1 \mathrm{~h}, 2 \mu \mathrm{L}$ of the solution was added to a $48 \mu \mathrm{L}$ solution of the primers designed from $\mathrm{Mj}-\mathrm{CP}$ cDNA sequence (forward, 5' ACTACACGGACTCCAGCCTCTTCG 3'; reverse, 5' GTAAGTCAGGGTGTAGGAGTGAGG $3^{\prime}$ ) in $1.5 \mathrm{mM} \mathrm{MgCl}_{2}, 0.25 \mathrm{mM}$ dNTP, and $0.5 \mathrm{U}$ ExTaq (Takara Shuzo Co., Japan). After amplifying by PCR at the annealing temperature of $55^{\circ} \mathrm{C}$ for $30 \mathrm{~s}$ ( $25-40$ cycles), the $376 \mathrm{bp}$ PCR products were examined on a $1.2 \%$ agarose gel. The primers $\beta$-actin-F ( $5^{\prime}$ ACGACATGGAGAAGATCTGG $\left.3^{\prime}\right)$ and $\beta$-actin-R ( $5^{\prime}$ GAAGCTCGTACGACTTCTCC $\left.3^{\prime}\right)$ were used to amplify a $489 \mathrm{bp} \beta$-actin fragment, which was used as an internal control [39]. The PCR reaction was the same as that described above.

\section{Results}

\subsection{Purification and characterization}

Purification of Mj-CP was achieved by two chromatographic steps (Fig. 1). The apparent molecular weight and purity of eluted proteins were analyzed by SDS-PAGE using $5 \%$ gel (Fig. 2A). Fractions 22-50 (peak II) contained mainly hemocyanin, and fractions 63-78 (peak IV) contained Mj-CP. About $15 \mathrm{mg}$ protein from peak IV was dialyzed against TE buffer, and then loaded on a Sepharose CL-6B column equilibrated with the same buffer. A major peak followed by a small shoulder was eluted from the column; it appeared to contain higher molecular weight forms of $\mathrm{Mj}$-CP since the mass of the major peak of Mj-CP was estimated to be about $0.8-1.2 \mathrm{MDa}$ based on elution volume from the column (Fig. 1B and inset). The $\mathrm{N}$-terminal sequence of the crosslinked bands excised from the gel could also be identified as Mj-CP. Some native Mj-CP dimers appeared to be crosslinked into tetramers and hexamers during collection and handling of the hemolymph.

\subsection{Oligomerization of $\mathrm{Mj}-\mathrm{CP}$ by hemocyte lysate}

To test whether it was the transglutaminase substrate capable of clotting, $1 \mu \mathrm{l}$ hemocyte lysate was added to $10 \mu \mathrm{g}$ purified $\mathrm{Mj}-\mathrm{CP}$ in $30 \mu \mathrm{l}$ of $50 \mathrm{mM}$ Tris- $\mathrm{HCl}(\mathrm{pH} 8.0)$ with $0.1 \mathrm{M} \mathrm{NaCl}$, and reaction was started by the addition of $1 \mu \mathrm{l}$ $0.3 \mathrm{M} \mathrm{CaCl}_{2}$. After incubation for 1 and $5 \mathrm{~min}$, the reaction was stopped and analyzed by SDS-PAGE under reducing condition (Fig. 2B). It was found that $\mathrm{Mj}$-CP oligomerized in $1 \mathrm{~min}$ while most of the protein transformed into insoluble clots in $5 \mathrm{~min}$.

\subsection{Full sequence of $\mathrm{Mj}-\mathrm{CP}$}

The N-terminal 1-15 amino acid sequence of purified Mj-CP was determined as LQPGLEYQYDYDAXV by automated sequencing. It shares up to $80 \%$ similarities to those of CPs of other shrimps $[10-14,26]$. It was found that the antiserum
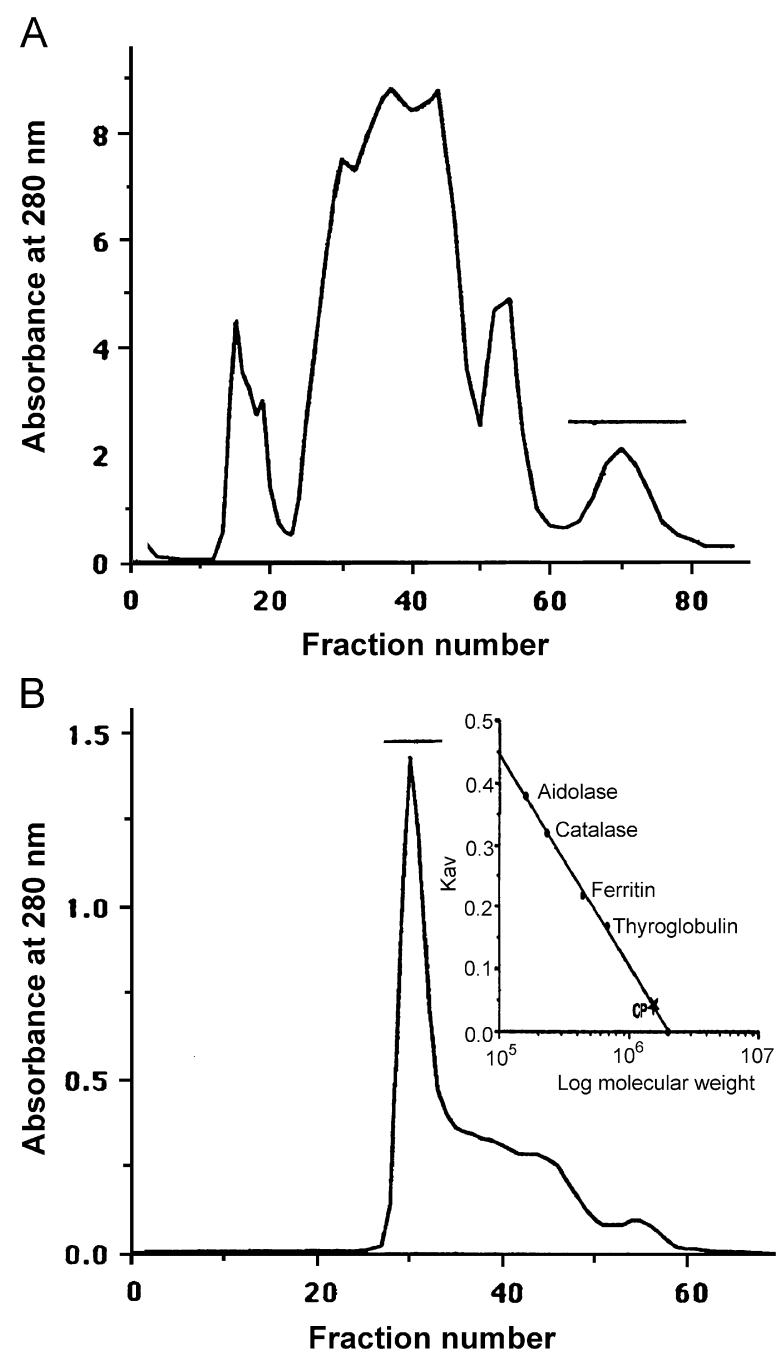

Fig. 1 Purification of $\mathrm{Mj}-\mathrm{CP}$ at $4{ }^{\circ} \mathrm{C}$. (A) DEAE ion exchange chromatography of $M$. japonicus plasma. Elution was carried out with $50 \mathrm{mM}$ Tris- $\mathrm{HCl}$ ( $\mathrm{pH} 8.0$ ) containing $1 \mathrm{mM}$ EDTA followed by a gradient of $0-0.4 \mathrm{M} \mathrm{NaCl}$; fractions of $4 \mathrm{ml}$ were collected. (B) Further gel filtration of $\mathrm{Mj}-\mathrm{CP}$ on Sepharose $\mathrm{CL}-6 \mathrm{~B}$ equilibrated with $1 \mathrm{mM}$ EDTA in $50 \mathrm{mM}$ Tris- $\mathrm{HCl}(\mathrm{pH} 8.0)$. Fractions of $2.2 \mathrm{ml}$ were collected. Bars denote fractions capable of clotting. Inset: the native molecular weight of $\mathrm{Mj}$-CP was estimated by its elution volume from this column, as calibrated with elution volumes of four marker proteins.

against $P$. monodon $\mathrm{CP}$ could cross-react with $\mathrm{Mj}-\mathrm{CP}$ in immuno-diffusion and Western blot analyses [7]. Degenerate PCR primers (Table 1) were useful for cloning Mj-CP. Three clones encoding the $\mathrm{N}$-terminal and the $\mathrm{C}$-terminal sequences of $\mathrm{Mj}$-CP were isolated (CP1, CP2, and CP5, Fig. 3). An internal cDNA fragment of 3208 bp was also amplified by PCR (CP4, Fig. 3). The full length of the CP CDNA was completed by $5^{\prime}$ RACE and $3^{\prime}$ RACE (CP3 and CP6, Fig. 3). Six clones were isolated and sequenced to complete the entire 5660 bp cDNA sequence of Mj-CP (accession no. DQ915453). According to Kozak's rule [40], the putative initiating codon ATG is at nucleotide 82 . The open reading frame contains a 14-residue signal peptide followed by Mj-CP of 1671 amino acids, which has a predicted mass of $188,420 \mathrm{Da}$ and an 
A

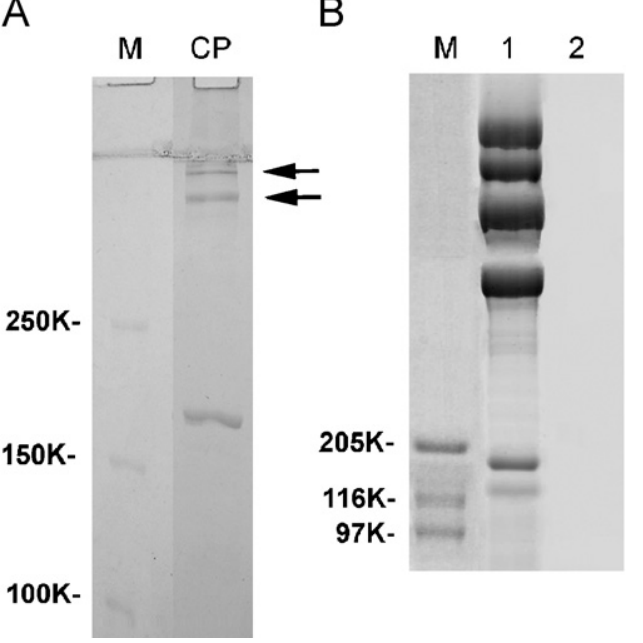

Fig. 2 SDS-PAGE analyses. (A) Purified Mj-CP on 5\% polyacrylamide gel; (B) polymerization of $\mathrm{Mj}$-CP by hemocyte lysate and $\mathrm{Ca}^{2+}$. A $2.5 \%$ polyacrylamide/agarose gel was used; lane 1, purified Mj-CP was clotted by hemocyte lysate; lane 2, supernatant after centrifugation of the clotted sample. Arrows indicate cross-linked form of $\mathrm{CP}$.

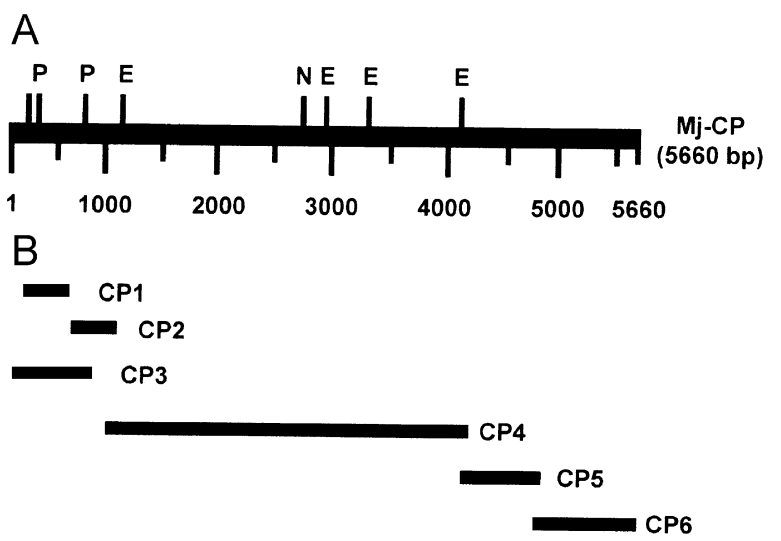

Fig. 3 Restriction enzyme map (A) and cloning strategy (B) of $\mathrm{Mj}$-CP CDNA. Oligonucleotides CP1, CP2, CP4, and CP5, were obtained by PCR. CP3 and CP6 were obtained by 5' RACE and $3^{\prime}$ RACE, respectively. Abbreviations of restriction enzyme sites are denoted as E, EcoRI; N, Ncol; P, Pstl.

isoelectric point of 5.6 (Fig. 4). However, the $N$-terminal sequence of $\mathrm{Mj}$-CP was deduced as LQPGLEYQYRYSARV based on its CDNA, while it was determined as LQPGLEYQYDYDAXV by protein sequencing. The discrepancies at residues 10 $(D / R)$ and 12 (D/S) may be due to errors in the identification of PTH-amino acid released in the two steps since residues 10 and 12 are conserved as $R$ and $S$ in the other three shrimp $\mathrm{CP}$, or possible geographic variations of the shrimps due to different batches of $M$. japonicus specimens used in cloning and hemolymph collection.

\section{4. cDNA cloning of Lv-CP}

Similar cloning strategy and primers (Table 2) were successfully used to clone the LV-CP gene of white shrimp,
L. vannamei. The cDNA has a total length of $5541 \mathrm{bp}$, including an open reading frame of 4998 bp (DQ984182). According to Kozak's rule [40], the putative initiating codon ATG is at nucleotide 83 . The open reading frame is predicted to encode a protein of 1666 amino acids $(188,064 \mathrm{Da})$ and an isoelectric point of 5.2 (Fig. 4). The amino acid sequences of several fragments previously published for Lv-CP [41] also match the sequence predicted from LV-CP CDNA.

\subsection{Sequence comparison and phylogenetic analysis}

Amino acid sequences of four crustacean CPs so far solved were aligned in Fig. 4. The predicted $\mathrm{Mj}$-CP sequence is $80.6 \%, 80.3 \%$, and $37.5 \%$ identical to those of CPs of white shrimp, tiger shrimp, and crayfish, respectively. These CPs appear to be homologous to insect VTGs and share low sequence similarities with other lipoproteins (e.g. mammalian apolipoprotein $B$ and microsomal triglyceride transfer protein) $[10,25]$. Like insect VTGs, the crayfish CP contains a conserved but possibly non-functional proteolytic processing site RXRR [25]; however, this site is absent in the CPs of penaeid shrimps.

A phylogenetic tree was constructed based on amino acid sequences of four CPs and the VTGs of various species including representative vertebrates, insects, and shrimps (Fig. 5). High bootstrap values on all nodes ( $\geqslant 78 \%)$ suggest robustness of the tree. All CPs are in a distinct cluster and penaeid CPs are more closely related to each other than to crayfish CP in this tree, suggesting that crustacean CP genes and VTG genes have evolved divergently.

\subsection{RT-PCR and tissue expression profile}

The expression patterns of Mj-CP mRNA in various tissues of M. japonicus were analyzed by RT-PCR. As shown in Fig. 6, a 376 bp DNA fragment could be amplified, in contrast to the negative control. The expression levels were highest in subcuticular epidermis, moderate in gill, CNS, eyestalk, heart, muscle, and lymphoid organ, and lowest in hepatopancreas, hemocyte, and intestine (Fig. 6).

\section{Discussion}

In shrimps, coagulation is initiated by the release of hemocyte transglutaminase, which effectively polymerizes the hemolymph CP to form stabilized gel [17]. Mj-CP was purified (Fig. 1), and it formed stable clots in the presence of $\mathrm{Ca}^{2+}$ and hemocyte transglutaminases, as shown by SDSPAGE analysis of Mj-CP (Fig. 2B). By RT-PCR analysis, Mj-CP was found to be expressed in most shrimp tissues, especially in the sub-cuticular epidermis, gill, CNS, and heart (Fig. 6). The finding was similar to the tissue expression profiles of tiger shrimp CP [43]; the present study further shows that shrimp epidermis is an important expression site of CP.

$M j-C P$ was eluted from the anion exchanger at higher concentration than most other plasma proteins of M. japonicus (Fig. 1A), consistent with its predicted $\mathrm{pl}$ of 5.6. It was further purified by a Sepharose CL-6B gel filtration column (Fig. $1 \mathrm{~B}$ ). The molecular mass of $\mathrm{Mj}-\mathrm{CP}$ is estimated to be $390 \mathrm{kDa}$ (Fig. 2), which is slightly smaller 


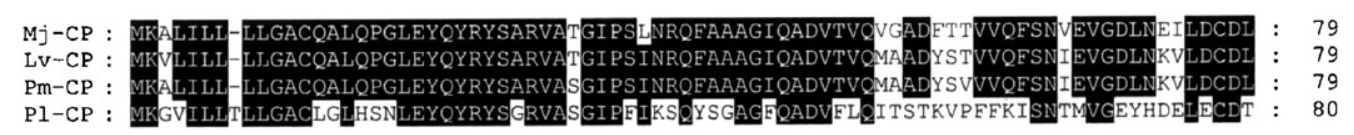

***

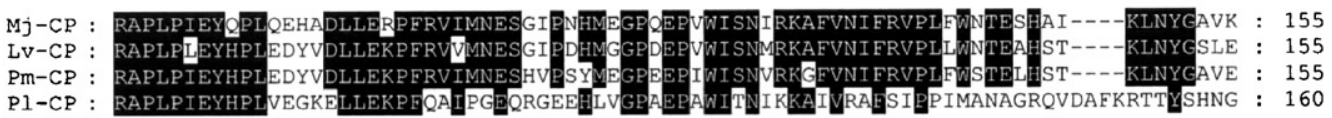
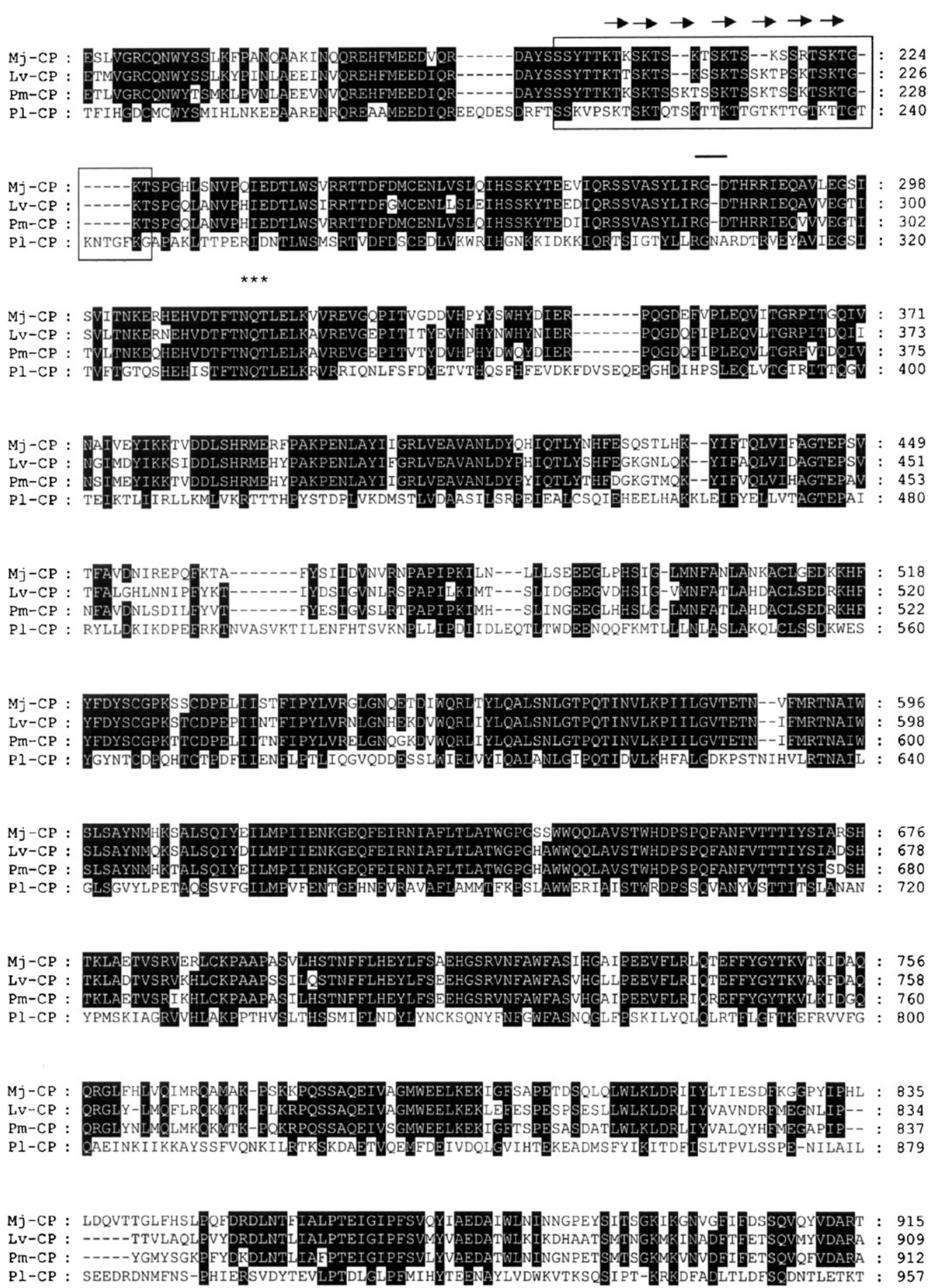

Fig. 4 Alignment of crustacean CP sequences. The sequences of Mj-CP (DQ915453) and Lv-CP (DQ984182) and those from tiger shrimp (Pm-CP, AAF19002) and crayfish (PI-CP, AAD16454) were compared. Gaps (-) are added to improve alignment. Residues that are identical in three sequences are shown in black. The Lys-rich and Gln-rich regions are boxed. Arrowheads indicate the Ser-Lys-Thr repeats. Asterisks and bars above the residues denote the conserved N-glycosylation sites and conserved RGD motifs, respectively. 

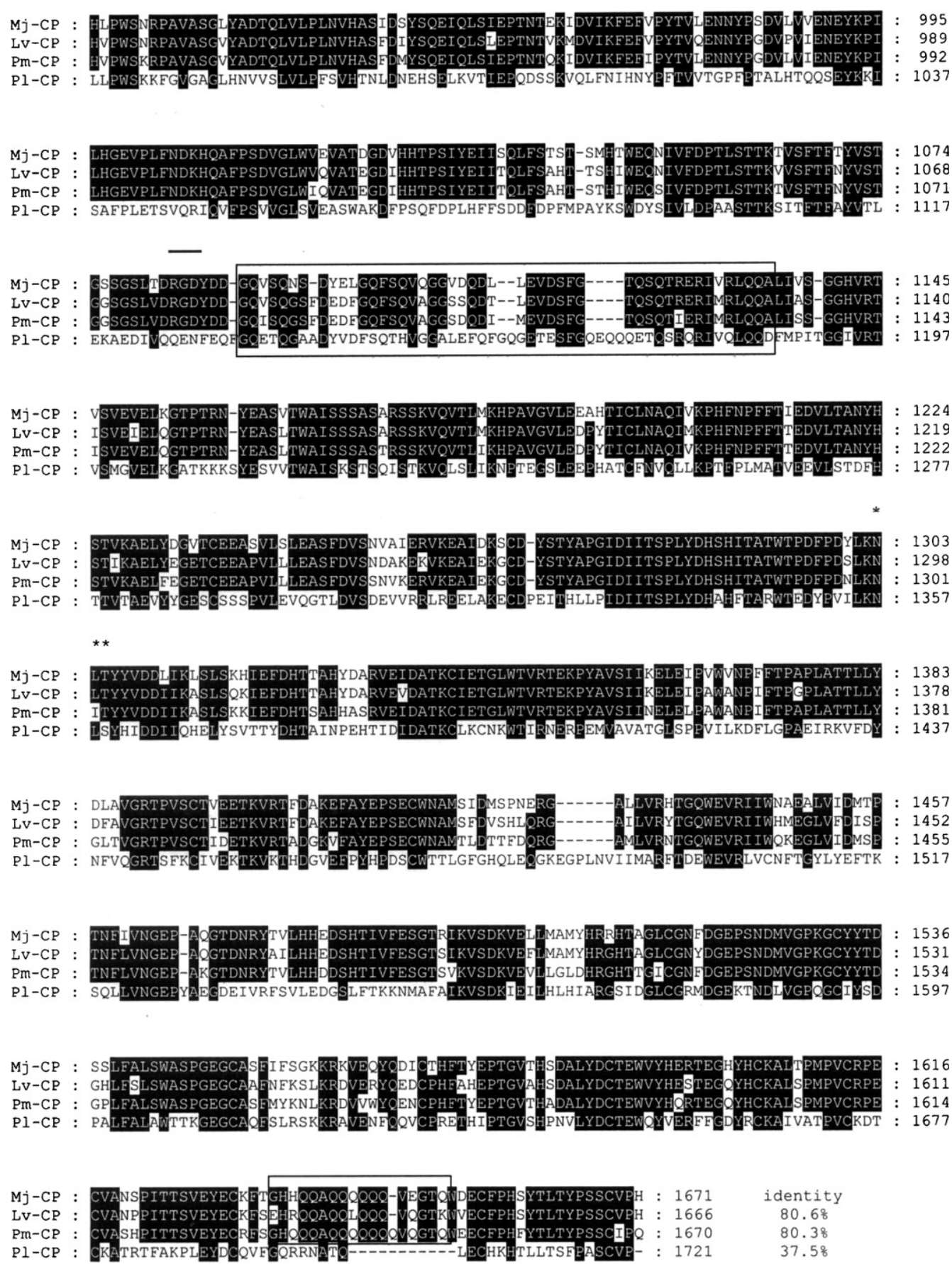

Fig. 4 (Continued)

than those reported for CPs of lobster [8], white shrimp [41], and crayfish [4], but slightly higher than that of tiger shrimp [6]. In analogy to the tiger shrimp CP [17], purified Mj-CP was a glycoprotein, high-mannose type of $\mathrm{N}$-glycans could explain for the mass increase of $13 \mathrm{kDa}$ for the predicted $\mathrm{CP}$ dimer protein of $377 \mathrm{kDa}$. A minor $180 \mathrm{kDa}$ degradation form of $\mathrm{Mj}-\mathrm{CP}$, bearing identical $\mathrm{N}$-terminal sequences as the native $195 \mathrm{kDa}$ subunit, was detected in purified $\mathrm{Mj}-\mathrm{CP}$. Similar degraded forms were also found during purification of crayfish CP [14] and tiger shrimp CP [7].

Apparently, the CP genes of marine penaeid shrimps were highly conserved. Similarity between sequences of tiger shrimp CP and Mj-CP is about $80 \%$ (Fig. 4). Their protein hydrophobicity profiles were also similar [10], and no extensive hydrophobic region or membrane-spanning domain can be identified in both molecules (Fig. 7). By immunodiffusion, we showed that the hemolymph of M. japonicus could cross-react with the antibodies against tiger shrimp CP [6]. As a substrate for hemocyte transglutaminase, shrimp CPs contain lysine and glutamine side chains to be cross-linked into isopeptide bonds. According to the substrate specificity of mammalian transglutaminase [44-46], we predict that special regions of the shrimp CPs probably are involved in the clotting reactions: (a) a Lys-rich 


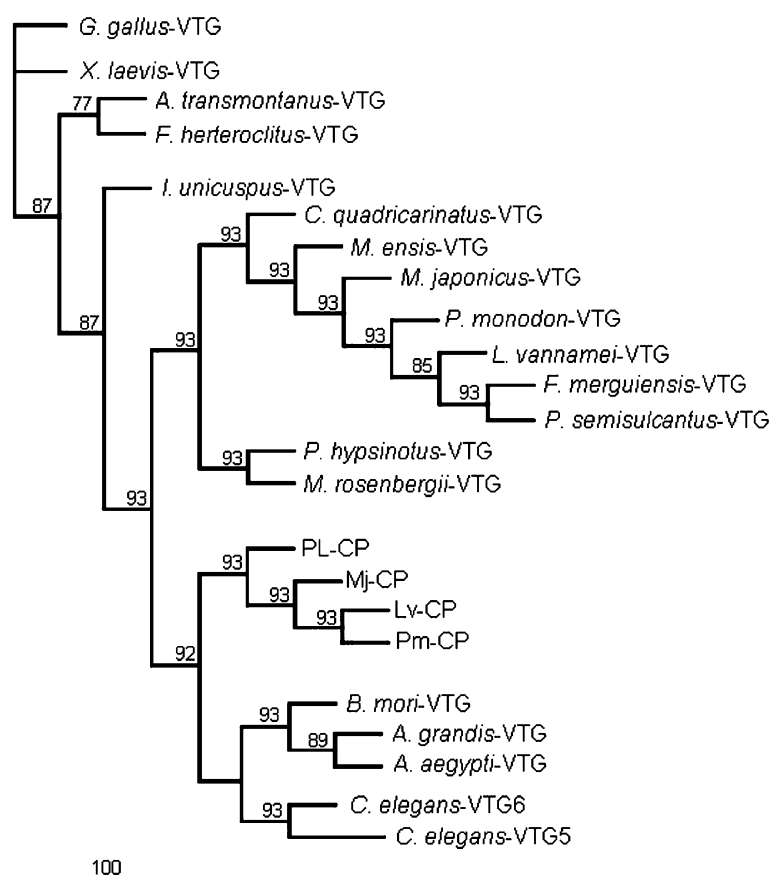

Fig. 5 Phylogenetic tree based on the amino acid sequences of representative VTGs and CPs. Species and GenBank accession nos. for the VTGs are white sturgeon, Acipenser transmontanus (AAA87392); yellow fever mosquito, Aedes aegypti (AAA18221; S46404); boll weevil, Anthonomus grandis (Q05808); silkworm moth, Bombyx mori (BAA06397); nematode, Caenorhabditis elegans (NP_508589 and AAC04423); mummichog, Fundulus heteroclitus (AAA93123); chicken, Gallus gallus (CAA31942); lamprey, Ichthyomyzon unicuspus (AAA49327); nine shrimp species including Fenneropenaeus merguiensis (AAR88442), Litopenaeus vannamei (AAP76571), Marsupenaeus japonicus (BAD98732), Macrobarchium rosenbergii (BAB69831), Metapenaeus ensis (AAT01139), Penaeus monodon (ABB89953), Penaeus semisulcatus (AAL12620), Pandalus hypsinotus (BAD11098), and Cherax quadricarinatus (AAG17936); frog, Xenopus laevis (CAA68433). The numbers at the nodes are bootstrap values.

A

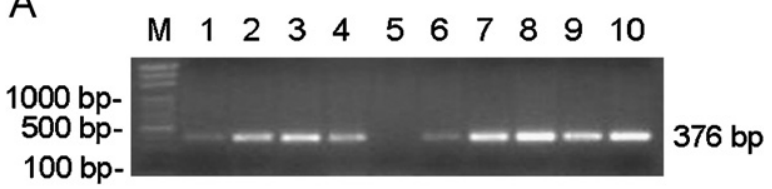

B

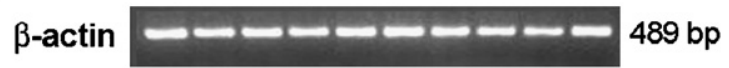

Fig. 6 Transcription of Mj-CP in various tissues. RT-PCR products were analyzed by electrophoresis on $1.5 \%$ agarose gel containing ethidium bromide. (A) CP-mRNA levels in Mj-tissues as analyzed by PCR amplification of a $376 \mathrm{bp}$ fragment of the mRNA. Lane 1, hemocyte; lane 2, muscle; lane 3, central nervous system; lane 4, lymphoid organ; lane 5, hepatopancreas; lane 6, intestine; lane 7, gill; lane 8, sub-cuticular epidermis; lane 9, eyestalk; lane 10, heart. (B) As an internal control, $\beta$-actin mRNA in each tissue was amplified.

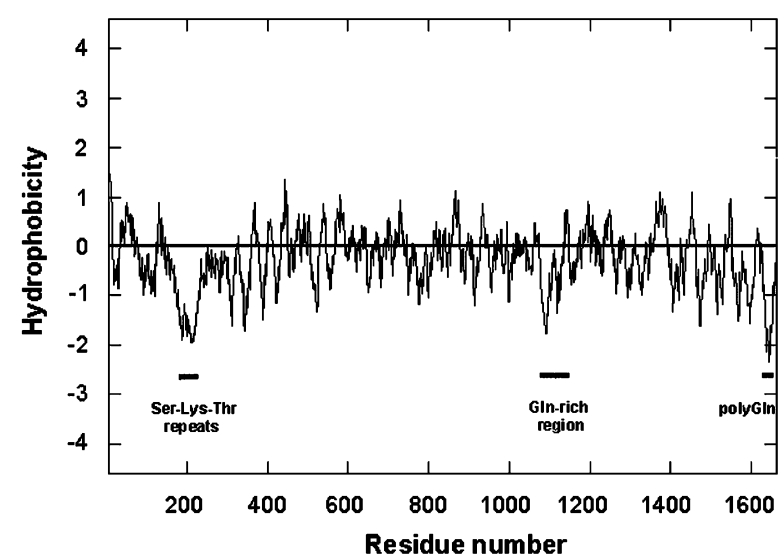

Fig. 7 Hydropathic profile of the Mj-CP. The average hydrophobicities over seven residues were calculated [36] along the entire amino acid sequence of $\mathrm{Mj}$-CP. Potential sites of crosslinking by transglutaminase were marked.

stretch at residue positions 200-250, which contain about seven Ser-Lys-Thr (SKT or TKT) repeats; (b) a Ser- and Glnrich region at positions 1100-1200; and (c) a polyGln stretch containing 8-11 Gln residues (e.g. XQQAQQQQQQVQGTQ) near the $\mathrm{C}$-terminus (Fig. 4). These stretches reside in the major hydrophilic regions of $\mathrm{Mj}-\mathrm{CP}$, i.e. residues $175-238$, 368-376, 523-573, 1175-1248, 1467-1487, and 1619-1658 (Fig. 7). Thus, they presumably are exposed on the surface of CP molecules and accessible to the transglutaminase, allowing multiple linkages between the CP molecules or their subunits to form.

Remarkably, 10 cysteine residues and a GI/LCG motif (at position 1512-1771 of $\mathrm{Mj}-\mathrm{CP}$ ) are conserved in the C-terminal regions of CPs (Fig. 4). A similar motif (TCGLCG) was conserved in invertebrate and vertebrate VTGs, and in domains D1 and D2 of human von Willebrand factor (vWF) and domain D3 of human mucin $2[47,48]$. These D-domains play essential roles in the polymerization of mucin 2 and VWF, and are involved in the disulfide bonding between VWF subunits $[49,50]$. Possibly, the C-terminal regions of shrimp CPs are also involved in their dimerization or subunit interactions. There are two RGD motifs conserved in penaeid CPs (Fig. 4), but their functional significance is not clear. The binding of tiger shrimp CP to the hemocytes was not detected [10], although functional RGD-recognizing receptors on the granular hemocytes of crayfish have been reported [51].

Being the major constituent of the egg yolk of almost all oviparous animals, VTGs are huge (200-700 kDa) phosphoglycolipoproteins [22,24,52]. They display sequence similarity to crustacean CP [26] and other lipoproteins such as apolipoprotein B $[23,24]$, and microsomal triglyceride transfer protein [53]. The cladogram in Fig. 7 reveals the following: (i) All VTGs form a cluster and are related to each other according to the known biosystematics of vertebrate and invertebrate species [42]. (ii) All vertebrate VTGs are rather different from the invertebrate VTGs and CPs, and loop-out in the tree. (iii) VTG genes of terrestrial arthropods and nematode are closer to the crustacean CPs than to the crustacean VTGs. VTG and CP genes of marine or freshwater crustaceans probably are paralogous genes, which 
have been diverged before the merging of terrestrial arthropods or insects. Thus, CPs possibly were derived from ancient animal VTG-like molecules as suggested previously $[10,25]$, like VTGs of today's terrestrial invertebrates. Apparently, both CP and VTG are indispensable in crustacean species, and the CP and the VTG genes have been separately evolved before insect and crustacean split. In addition, we found that the CP mRNAs are expressed in most $M$. japonica tissues, while the sub-cuticular epidermis appears to be the tissue with the highest level of Mj-CP expression. This finding is in accord with the important role of $C P$ in the defense, healing, and growth of the shrimp.

\section{Acknowledgments}

We thank Dr. Yuh-Ling Chen for supplying peptide sequences of $M$. japonica CP. Financial supports and research grants were from National Science Council, ROC (92-2320-B-241003), Academia Sinica, and Hungkuang University, Taiwan.

\section{References}

[1] Theopold U, Schmidt O, Soderhall K, Dushay MS. Coagulation in arthropods: defense, wound closure and healing. Trends Immunol 2004;25:289-94.

[2] Kawabata SL, Muta T, Iwanaga S. The clotting cascade and defense molecules found in the hemolymph of the horseshoe crab. In: Soderhall K, Iwanaga S, Vasta GR, editors. New directions in invertebrate immunology. Fair Haven: SOS Publications; 1996. p. 255-83.

[3] Durliat M. Clotting process in crustacean decapoda. Biol Rev 1985;60:473-98.

[4] Martin GG, Hose JE, Omori S, Chong C, Hoodbhoy T, Mackrell N. Localization and roles of coagulogen and transglutaminase in hemolymph coagulation in decapod crustaceans. Comp Biochem Physiol 1991;100B:517-22.

[5] Bohn H, Barwig B. Hemolymph clotting in the cockroach Leucophaea maderae (Blattaria). Influence of ions and inhibitors; isolation of the plasma coagulogen. J Comp Physiol 1984;154B:457-67.

[6] Komatsu M, Ando S. A very high-density lipoprotein with clotting ability from hemolymph of sand crayfish, Ibacus ciliatus. Biosci Biotechnol Biochem 1998;62:459-63.

[7] Yeh MS, Chen YL, Tsai IH. The hemolymph clottable proteins of tiger shrimp, Penaeus monodon, and related species. Comp Biochem Physiol 1998;121B:169-76.

[8] Fuller GM, Doolittle RF. Studies of invertebrate fibrinogen. I. Purification and characterization of fibrinogen from the spiny lobster. Biochemistry 1971;10:1305-11.

[9] Fuller GM, Doolittle RF. Studies of invertebrate fibrinogen. II. Transformation of lobster fibrinogen into fibrin. Biochemistry 1971;10:1311-5.

[10] Yeh MS, Huang CJ, Leu JH, Lee YC, Tsai IH. Molecular cloning and characterization of a hemolymph clottable protein from tiger shrimp (Penaeus monodon). Eur J Biochem 1999;266: 624-33.

[11] Montano-Perez K, Yepiz-Plascencia G, Higuera-Ciapara I, Vargas-Albores $F$. Purification and characterization of the clotting protein from the white shrimp Penaeus vannamei. Comp Biochem Physiol 1999;122B:381-7.

[12] Perazzolo LM, Lorenzini DM, Daffre S, Barracco MA. Purification and partial characterization of the plasma clotting protein from the pink shrimp Farfantepenaeus paulensis. Comp Biochem Physiol 2005;142B:302-7.
[13] Yepiz-Plascencia G, Jime'nez-Veja F, Romo-Figueroa MG, Sotelo-Mundo RR, Vargas-Albores F. Molecular characterization of the bifunctional VHDL-CP from the hemolymph of the white shrimp Penaeus vannamei. Comp Biochem Physiol 2002;132B: 585-92.

[14] Kopacek P, Hall M, Soderhall K. Characterization of a clotting protein, isolated from plasma of the freshwater crayfish Pacifastacus leniusculus. Eur J Biochem 1993;213:591-7.

[15] Huang CC, Sritunyalucksana K, Soderhall K, Song YL. Molecular cloning and characterization of tiger shrimp (Penaeus monodon) transglutaminase. Dev Comp Immunol 2004;28: 279-94.

[16] Chen MY, Hu KY, Huang CC, Song YL. More than one type of transglutaminase in invertebrates? A second type of transglutaminase is involved in shrimp coagulation. Dev Comp Immunol 2005;29:1003-16.

[17] Yeh MS, Kao LR, Huang CJ, Tsai IH. Biochemical characterization and cloning of transglutaminases responsible for hemolymph clotting in Penaeus monodon and Marsupenaeus japonicus. Biochim Biophys Acta 2006;1764:1167-78.

[18] Wang R, Liang Z, Hall M, Soderhall K. A transglutaminase involved in the coagulation system of the freshwater crayfish, Pacifastacus leniusculus. Tissue localization and cDNA cloning. Fish Shellfish Immunol 2001;11:623-37.

[19] Hall M, van Heusden MC, Soderhall K. Identification of the major lipoproteins in crayfish hemolymph as proteins involved in immune recognition and clotting. Biochem Biophys Res Commun 1995;216:939-46.

[20] Kollman JM, Quispe RF. The $17 \AA$ structure of the $420 \mathrm{kDa}$ lobster clottable protein by single particle reconstruction from cryoelectron micrographs. J Struct Biol 2005;151: 306-14.

[21] Doolittle RF, Riley M. The amino-terminal sequence of lobster fibrinogen reveals common ancestry with vitellogenins. Biochem Biophys Res Commun 1990;167:16-9.

[22] Byrne BM, Gruber M, Ab G. The evolution of egg yolk proteins. Prog Biophys Mol Biol 1989;53:33-69.

[23] Chen JS, Sappington TW, Raikhel AS. Extensive sequence conservation among insect, nematode, and vertebrate vitellogenins reveals ancient common ancestry. J Mol Evol 1997;44: 440-51.

[24] Sappington TW, Raikhel AS. Molecular characteristics of insect vitellogenins and vitellogenin receptors. Insect Biochem Mol Biol 1998;28:277-300.

[25] Hall M, Wang R, van Antwerpen R, Sottrup-Jensen L, Soderhall $K$. The crayfish plasma clotting protein: a vitellogenin-related protein responsible for clot formation in crustacean blood. Proc Natl Acad Sci USA 1999;96:1965-70.

[26] Doolittle RF, Riley M. The amino-terminal sequence of lobster fibrinogen reveals common ancestry with vitellogenins. Biochem Biophys Res Commun 1990;167:16-9.

[27] Chen YL, Huang SH, Cheng JH, Tsai IH. Relationship between hemolymph coagulation and disease in shrimps: (II) Purification and characterization of the hemolymph coagulogen of penaeids (COA Fisheries Series, No. 40, Taipei, ROC). Fish Dis Res 1993;13:1-9.

[28] Bradford MM. A rapid and sensitive method for the quantitation of microgram quantities of proteins utilizing the principle of protein-dye binding. Anal Biochem 1976;72:248-54.

[29] Neville Jr. DM. Molecular weight determination of protein dodecyl sulfate complexes by gel electrophoresis in a discontinuous buffer system. J Biol Chem 1971;246:6328-34.

[30] Sambrook J, Fritsch EF, Maniatis T. Molecular cloning: a laboratory manual. Cold Spring Harbor, NY: Cold Spring Harbor Laboratory Press; 1989.

[31] Chomczynski P, Sacchi N. Single-step method of RNA isolation by acid guanidinium thiocyanate-phenol-chloroform extraction. Anal Biochem 1987;162:156-9. 
[32] Mullis KB, Faloona FA. Specific synthesis of DNA in vitro via a polymerase-catalyzed chain reaction. Methods Enzymol 1987;155:335-50.

[33] Sanger F, Nicklen S, Coulson AR. DNA sequencing with chainterminating inhibitors. Proc Natl Acad Sci USA 1977;74:5463-7.

[34] McGinnis S, Madden TL. BLAST: at the core of a powerful and diverse set of sequence analysis tools. Nucleic Acids Res 2004;32:W20-5.

[35] Thompson JD, Higgins DG, Gibson TJ. CLUSTAL W: improving the sensitivity of progressive multiple sequence alignment through sequence weighting, position-specific gap penalties and weight matrix choice. Nucleic Acids Res 1994;22:4673-80.

[36]. Felsenstein J. PHYLIP: the PHYLogeny Inference Package, version 3.573. Computer program distributed by the Department of Genetics, University of Washington, Seattle, 1992.

[37] Felsenstein J. Confidence limits on phylogenies: an approach using the bootstrap. Evolution 1985;39:783-91.

[38] Kyte J, Doolittle RF. A simple method for displaying the hydropathic character of a protein. J Mol Biol 1982;157: 105-32.

[39] Nagoshi H, Inagawa H, Morii K, Harada H, Kohchi C, Nishizawa $\mathrm{T}$, et al. Cloning and characterization of a LPS-regulatory gene having an LPS binding domain in kuruma prawn Marsupenaeus japonicus. Mol Immunol 2006;43:2061-9.

[40] Kozak M. An analysis of 50-noncoding sequences from 699 vertebrate messenger RNAs. Nucleic Acids Res 1987;15:8125-48.

[41] Montano-Perez K, Yepiz-Plascencia G, Higuera-Ciapara I, Vargas-Albores F. Purification and characterization of the clotting protein from the white shrimp Penaeus vannamei. Comp Biochem Physiol 1999;122B:381-7.

[42] Lavery S, Chan TY, Tam YK, Chu KH. Phylogenetic relationships and evolutionary history of the shrimp genus Penaeus s.l. derived from mitochondrial DNA Mol. Phylogenet Evol 2004;31:39-49.

[43] Yeh MS, Huang CJ, Cheng JH, Tsai IH. Tissue-specific expression and regulation of the hemolymph clottable protein of tiger shrimp (Penaeus monodon). Fish Shellfish Immunol 2007;23: 272-9.
[44] Groenen PJ, Smulders RH, Peters RF, Grootjans JJ, van de ljssel $\mathrm{PR}$, Bloemendal $\mathrm{H}$, et al. The amine-donor substrate specificity of tissue-type transglutaminase influence of amino acid residues flanking the amine-donor lysine residue. Eur J Biochem 1994;220:795-9.

[45] Grootjans JJ, Groenen PJ, de Jong WW. Substrate requirements for transglutaminase. J Biol Chem 1995;270:22855-8.

[46] Steinert PM, Marekov LN. The proteins elafin, filaggrin, keratin intermediate filaments, loricrin, and small proline-rich proteins 1 and 2 are isodipeptide cross-linked components of the human epidermal cornified cell envelope. J Biol Chem 1995;270:17702-11.

[47] Nose Y, Lee JM, Ueno T, Hatakeyama M, Oishi K. Cloning of cDNA for vitellogenin of the parasitoid wasp, Pimpla nipponica (Hymenoptera: Ichneumonidae). Vitellogenin primary structure and evolutioary considerations. Insect Biochem Mol Biol 1997;27:1047-56.

[48] Mouchel N, Trichet V, Betz A, Le Pennec JP, Wolff J. Characterization of vitellogenin from rainbow trout (Oncorhynchus mykiss). Gene 1996;174:59-64.

[49] Mayadas TN, Wanger DA. Vicinal cysteines in the prosequence play a role in von Willebrand factor multimer assembly. Proc Natl Acad Sci USA 1992;89:3531-5.

[50] Voorberg J, Fontijn R, van Mourik JA, Pannekoek H. Domains involved in multimer assembly of von Willebrand factor (VWF): multimerization is independent of dimerization. EMBO J 1990; 9:797-803.

[51] Johansson MW, Soderhall K. A peptide containing the cell adhesion sequence RGD mediates degranulation and cell adhesion of crayfish granular haemocytes in vitro. Insect Biochem 1989;19:573-9.

[52] Valle D. Vitellogenesis in insects and other groups-a review. Mem Inst Oswaldo Cruz 1993;88:1-26.

[53] Leiper JM, Bayliss JD, Pease RJ, Brett DJ, Scott J, Shoulders CC. Microsomal triglyceride transfer protein, the abetalipoproteinemia gene product, mediates the secretion of apolipoprotein B-containing lipoproteins from heterologous cells. J Biol Chem 1994;269:21951-4. 